\title{
Análisis actual y orientaciones futuras del proceso contencioso-administrativo
}

RAFAEL FERNANDEZ MONTALVO

Vocal del Consejo General del Poder Judicial

La organización de la jurisdicción contencioso-administrativa o, más ampliamente, el sistema de lo contencioso-administrativo ha sido una de las cuestiones polémicas que durante el siglo XIX se vincula a los diferentes programas políticos, dándose diversas soluciones según que la tendencia fuera progresista o moderada. Así puede decirse que nuestra legislación ha incorporado en diversos momentos históricos los distintos sistemas que ofrece el Derecho comparado.

La Constitución de Bayona, como primer antecedente, y la Constitución de Cádiz de 1812 contemplan la existencia de un Consejo de Estado, pero nada suponen en orden a la creación de órganos encargados del conocimiento de los litigios contencioso-administrativos.

Las leyes de 1845 (2 de abril y 16 de septiembre) intentan, por primera vez, dar respuesta a la "necesidad de una jurisdicción especial, distinta en la esencia y en la forma de la jurisdicción ordinaria, que pueda conocer de los negocios contencioso-administrativos". Introducen el sistema administrativo francés de jurisdicción retenida encomendan- 
do el conocimiento de dichos asuntos al Consejo de Ministros presidido por el Rey, quien pronunciaba sentencia en forma de Real Decreto, acorde o no con el Consejo Real, que más tarde pasaría a denominarse Consejo de Estado. Por su parte, los Consejos Provinciales, presididos por los Jefes Políticos, enjuiciaban en primera instancia las reclamaciones contra las resoluciones de la Administración Local.

Los Decretos de 1868 (13 y 16 de octubre) incorporan una de las preocupaciones del liberalismo decimonónico y del sector progresista estableciendo un sistema judicial en el ámbito contencioso-administrativo. La Revolución de Septiembre hizo posible este cambio legislativo que supuso la supresión de las competencias en esta materia de los Consejos Provinciales y del Consejo de Estado y su atribución a la Jurisdicción ordinaria mediante el establecimiento de Salas en las Audiencias Territoriales y en el Tribunal Supremo. Del sistema administrativo se pasa, pues, al sistema judicial de jurisdicción ordinaria.

La Restauración, mediante Decreto de 20 de enero de 1875, supuso el retorno al sistema anterior, devolviendo al Consejo de Estado la jurisdicción contencioso-administrativa en su expresión suprema y encomendando la misma jurisdicción en su grado inferior a las Comisiones provinciales, como sucesores de los antiguos Consejos.

Las leyes de 1888 y 1894 (18 de septiembre y 22 de julio, respectivamente) representan la fórmula mixta o transaccional identificada con Santamaría de Paredes. Crearon los Tribunales provinciales de lo contencioso-administrativo y el Tribunal de lo Contencioso-administrativo del Consejo de Estado, que acabó convirtiéndose en una Sala del Tribunal Supremo.

La esencia del sistema consistía en la provisión de los puestos de Magistrados de dichos Tribunales con miembros de la carrera judicial y de la carrera administrativa. El sistema tomó carta de naturaleza en el Derecho español llegando con reformas de escasa trascendencia hasta la Ley de 27 de diciembre de 1956. 
La Ley Reguladora de la Jurisdicción Contencioso-Administrativa (LJCA), de 27 de diciembre de 1956, ha merecido una elogiosa crítica doctrinal.

En primer lugar, supuso la consagración de un sistema caracterizado por la plena judicialización, colegiación, especialización y regionalización de los órganos competentes para el control de la actividad administrativa, contribuyendo, al menos parcialmente, a la realización de una de las exigencias del Estado de Derecho: el sometimiento de la Administración al ordenamiento jurídico.

En segundo lugar, desde el punto de vista técnico representó importantes logros acrecentados, en ocasiones, por aportaciones jurisprudenciales. Introdujo modernas concepciones del Derecho Administrativo y del Derecho Procesal, como la delimitación de lo contencioso-adıninistrativo, la referencia a la pretensión procesal, el establecimiento de un procedimiento ágil y, al mismo tiempo, respetuoso con las garantías procesales, y la continua apelación al principio antiformalista que refleja su Exposición de Motivos. Todo ello hizo posible un aceptable funcionamiento de la jurisdicción.

La larga vigencia de la Ley de 1956 se explica por dicha perfección técnica y por su propia modernidad en relación con las leyes procesales. Pero ello no quiere decir que el ordenamiento procesal contencioso-administrativo no haya sufrido, durante este largo lapso de tiempo, modificaciones importantes, a veces por vía legislativa, a veces por vía de aportaciones jurisprudenciales.

Así, entre las primeras pueden señalarse: la atribución a la jurisdicción civil de las cuestiones sobre responsabilidad patrimonial de la Administración en materia de Derecho privado (art. 41 LRJAE de 26 de julio de 1957); modificación del silencio administrativo y prohibición de la doble alzada (arts. 1.3, 94, 95, 122.2 y 125.1 LPA, de 17 de julio de 1958); aumento de la competencia de las Salas de las Audiencias Territoriales (L. 10/1973, de 17 de marzo); creación de la Sala de lo 
Contencioso-administrativo de la Audiencia Nacional (RDL 1/1977, de 4 de enero) y la regulación del proceso especial de protección de los derechos fundamentales de la persona (Ley 62/1978, de 26 de diciembre).

Como modificaciones derivadas de la jurisprudencia o de la doctrina del Tribunal Constitucional pueden citarse, sin ánimo exhaustivo: exclusión de zonas inmunes a la jurisdicción (ATC 60/1980); establecimiento de la necesidad de emplazamiento personal de los demandados (STC 9/1981 y 63/1982, entre otras muchas); extensión de la legitimación (STC 60/1982); redefinición del concepto de acto político (STC 63/1983); y eliminación de pautas formalistas en la admisión de los recursos.

La subsanación de los defectos procesales prevista en diversos arts. de la LJCA (arts. 57.3, 62.2, 72.2 y 129) debe entenderse en el sentido amplio que exigen los arts. $24.1 \mathrm{CE}, 11.3$ y 243 LOPJ. Dichos preceptos, como recuerda una STC de 15 de diciembre de 1987, no reconocen un derecho a la subsanación en todo caso, pero únicamente permiten a los Tribunales abstenerse de resolver sobre las pretensiones que se formulen cuando el defecto fuere insubsanable o no se subsanare por el procedimiento establecido en las leyes. E, incluso, la STC 162/1986 ha señalado que la posibilidad de subsanar un defecto procesal no depende de la existencia de previsiones legislativas para cada procedimiento, sino del mismo contenido normativo del art". 24.1 CE.

La decisión judicial que se limita a acordar la retroacción del expediente para que, subsanados los defectos formales, se dicte un nuevo acto administrativo, debe tener carácter excepcional. Sólo producen la nulidad de actuaciones administrativas las infracciones formales que perjudiquen el derecho de defensa de los interesados o que, privando de elementos esenciales de conocimiento, puedan variar el contenido del acto.

Debe abandonarse la vieja interpretación mitificada del carácter revisor de la jurisdicción contencioso-administrativa que comportaba la afirmación de que el Tribunal no podía sustituir a la Administración reformando los actos y disposiciones recurridas y pronunciarse realmente sobre la cuestión de fondo realmente suscitada, esto es, declarando cuáles son los derechos concretos del recurrente en relación con el acto de la Administración, si dis- 
pone de elementos suficientes para tal pronunciamiento y respetando, no obstante, lo que es el núcleo de la discrecionalidad técnica y administrativa.

Pero, en los momentos actuales se habla de crisis del proceso contencioso-administrativo en un doble sentido.

Desde un punto de vista cuantitativo, como consecuencia de la inadecuación de la estructura orgánica al incremento de la conflictividad administrativa. Baste decir que entre 1981 y 1988 se produce un aumento del $217,82 \%$ del número de asuntos ingresados. Lo que quiere decir que, para mantener los niveles prestacionales del año 1981 hubiera sido necesario incrementar en la misma proporción los medios personales y materiales.

Los datos sobre el retraso y acumulación de asuntos en los Tribunales contencioso-administrativos son abrumadores.

En 1990 en las Salas de lo contencioso-administrativo de España, con excepción del Tribunal Supremo (TS) y Audiencia Nacional (AN). se registraron 55.922 asuntos, que pasaron a 61.103 en 1991, 72.858 en 1992 y 67.728 hasta el 30 de septiembre de 1993. La cifra de dependencia en esta fecha era de 128.027 asuntos.

Desde el punto de vista cualitativo, la misma masificación de los procesos trae consigo un notable descenso en al calidad de la justicia, administrativa tanto en tiempo como en contenido. De esta circunstancia del contencioso-administrativo, que no es peculiar de nuestro sistema sino que es un fenómeno general en otros países del área continental, derivan dos consecuencias:

A. La tendencia a la inversión del principio, hasta ahora dogmático, de la necesidad de suprimir las vías administrativas previas mediante la inclinación a convertir en algunos casos la vía administrativa en un mecanismo de evitación del proceso al que debe acudirse preceptiva o facultativamente, como se advierte en la legislación europea comparada.

B. Necesidad de regular diversos aspectos del proceso relacionados con los actos masa o actos administrativos de contenido idéntico que afectan a gran número de personas.

Pero, además, en nuestro ordenamiento resulta inaplazable el esta- 
blecimiento de un nuevo marco jurídico que adecúe plenamente el modelo contencioso-administrativo a las exigencias constitucionales.

No se trata de olvidar las bondades y aciertos del texto de 1956 por un prurito pendular en el cambio, sino de superar algunas quiebras y restricciones del contencioso-administrativo para la eficaz defensa de los derechos e intereses legítimos de los ciudadanos en una articulación compatible con la defensa del interés público, no confiando solamente a la función creadora de la interpretación jurisprudencial la necesaria adaptación de la Ley en los no pocos extremos que evidencian las resoluciones del Tribunal Constitucional y del Tribunal Supremo.

Las consecuencias de los arts. 24.1, 106.1 y 117.3 CE en el ámbito contencioso-administrativo han sido de tal magnitud que permiten hablar. incluso, de una nueva concepción superadora de la idea tradicional del "proceso al acto" o de mera protección de la legalidad objetiva, para convertirse en una justicia de tutela de oposiciones jurídicas subjetivas, de derechos e intereses legítimos, según expresa el citado art". $24.1 \mathrm{CE}$.

La Ley 10/1992, de 30 de abril, de medidas de reforma del proceso civil, del penal y contencioso-administrativo regula. en este ámbito el recurso de casación, que sustituye al recurso de apelación con la introducción de un trámite riguroso de admisión y el establecimiento del límite cuantitativo fijado para la casación civil.

Al margen de esta novedad, en el Parlamento se introdujo una nueva regulación del emplazamiento en el proceso contencioso-administrativo, que supone la realización del mismo por parte de la Administración.

Uno de los defectos de la LICA lue la regulación del emplazamiento de los demandados, para el que, según el primitivo sistema, hastaba la publicación en los Boletines Oliciales del anuncio de la interposición del recurso, sin necesidad de emplazamiento individual. Este sistema fue considerado por el TC, desde sus primeras sentencias contrario al derecho a la tutela judicial efectiva, y de ahí la modificación de los arts. 64 y $66 \mathrm{LJCA}$.

Sin prescindir de la publicación de los edictos en los Boletines Oficiales (art". 60), se impone a la Administración autora del acto, la obligación de notificar a cuantos aparezcan como interesados en el expedien- 
te, la remisión de éste al Tribunal, emplazándoles para que puedan comparecer y personarse en autos en el plazo de nueve días. Lna vez recibido el expediente, el Tribunal debe comprobar que se han ef'ectuado los debidos emplazamientos. y si advierte que son incompletos. ordenará que se practiquen los necesarios.

III

La mencionada Ley 10/1992 es una ley fragmentaria que no satisface las necesidades de regulación, en la doble vertiente orgánica y procesal, que padece desde hace años el orden jurisdiccional contencioso-administrativo. Por ello, su Exposición de Motivos señala que su limitada iniciariva de reforma del contencioso "no obstará para que se continúen realizando cuantas actuaciones son necesarias para la mejor adtecuación de este procedimiento".

Parece, por tanto, fuera de toda duda la necesidad de una reforma o actualización profunda del proceso contencioso administrativo mediante una modificación sustancial de la IJJCA o, incluso, a través de la promulgación de una nueva Ley reguladora, que es la opción elegida por el Ministerio de Justicia e Interior en el que se ha claborado un anteproyecto de dicha ley por una Comisión de cualificados juristas, sobre el que el Consejo General del Poder Judicial ha tenido ya ocasión de formular el correspondiente informe.

En cualquier caso, la nueva regulación del contencioso-administrativo debe contemplar las siguientes cuestiones:

1. Ámbito de la jurisdicción contencioso-administrativa.

A. El art". $24.1 \mathrm{CE}$, que consagra la general tutela judicial efectiva, y el art". 106.1 CE. que se refiere al control por los Tribunales de la legalidad de "la actuación administrativa" sirven de apoyo para evitar las consecuencias de un presupuesto marcadamente subjetivo al señalar la extensión de la jurisdicción, en los términos en que resultan de la actual redacción de los arts. $1 \mathrm{~L}$ LICA y 9.4 LOP.J. Además de la lógica inclusión de la Administración de las Comunidades Autónomas, efectuada por la Ley 
34/1981, de 5 de octubre, la Ley reguladora del proceso contencioso administrativo debe reflejar el fenómeno expansivo de la jurisdicción: la atribución del contencioso-electoral (arts. 109 y ss. de la LO 5/1985, de 19 de junio, del Régimen Electoral General, modificada por las LL.OO 1/1987 y 8/1991) y el conocimiento que le corresponde de los recursos contra actos en materia de personal y gestión patrimonial de los órganos de gobierno del Congreso de los Diputados, del Senado (art". 49.3 Estatuto del Personal de las Cortes Generales, de 26 de junio de 1989), del Tribunal Constitucional (art ${ }^{\circ} .99$ LOTC), del Consejo General del Poder Judicial (art. 143 LOPJ), del Tribunal de Cuentas y del Defensor del Pueblo.

B. a) Como cuestiones expresamente excluidas de la jurisdicción contencioso-administrativa deben figurar, además de las que actualmente señala el art $^{\circ} .2 \mathrm{LJCA}$, las atribuidas con carácter exclusivo al Tribunal Constitucional y el llamado recurso contencioso-disciplinario militar atribuido a la jurisdicción militar.

b) Pero, sobre todo, la nueva normativa debe encontrar una formulación precisa de los actos políticos exentos del control jurisdiccional contencioso-administrativo, respecto de los que se ha producido una reducción conceptual en la doctrina y en la jurisprudencia, pero sin llegar a su supresión.

La jurisprudencia, en una primera interpretación del art”. 2.b) LJCA, siguió para caracterizar el acto político la doctrina del móvil político, aplicándola a las sanciones de orden público e, incluso, a los reglamentos en cuanto expresión de una determinada opción política.

En los años sesenta el Tribunal Supremo abandona el criterio del móvil político y atiende, para precisar la exclusión establecida en el citado art". 2.b) LJCA, a la concurrencia de un doble requisito: subjetivo, que fuera dictado por el Gobierno en su unidad, es decir, por el Consejo de Ministros; y, objetivo, que fuera también la expresión unitaria de los poderes del Estado, en el que el contenido y finalidad resultara diferenciada de la actividad realmente administrativa al proyectarse sobre asuntos trascendentes de índole general (SSTS 10 de febrero 1962, 15 de marzo 1965 y 3 de enero de 1979, entre otras), esto es, decisiones que afectasen al conjunto del Estado. 
Después de la Constitución, el TC ha reconocido en diversas ocasiones la existencia de actos políticos, no susceptibles de control judicial, esencialmente distintos de los actos administrativos (SSTC 63/1983, $68 / 1985$ y $39 / 1989$, entre otras).

La STC 45/1990, aunque sustituyendo la expresión "acto político" por la de "actuaciones no sometidas a Derecho administrativo", incluye en esta categoría: las decisiones del Gobierno a través de las cuales cumple la función de dirección política que atribuye el art". $97 \mathrm{CE}$, como las decisiones que otorgan prioridad a unas $u$ otras parcelas de la acción que le corresponde, salvo que tal prioridad resulte obligada en ejecución de lo dispuesto en las leyes. Y la STC 196/1990 considera exentos de control los actos producidos en el seno de las relaciones políticas entre Ejecutivo y Legislativo, tanto entre Gobierno y Cortes como entre Ejecutivos autonómicos y Asambleas Legislativas. Se daba así respaldo a un criterio doctrinal que considera como actos políticos los que corresponden al Gobierno como órgano constitucional en sus relaciones con los demás órganos constitucionales o poderes del Estado, además de los que se producen en el ámbito de las relaciones internacionales.

Así, de manera casuística el TC ha apreciado la noción del acto político en los siguientes supuestos:

- Desestimación presunta por el Consejo de Ministros, en virtud de silencio administrativo negativo, de solicitud de medios personales y materiales para la Administración de Justicia en el País Vasco formulada por los Decanos de los Colegios de Abogados de Vizcaya, Álava y Guipúzcoa (STC 45/1990).

- Contestación del Gobierno Vasco a solicitud de información parlamentaria (STC 196/1990 y 220/1991).

El Tribunal Supremo, por su parte, también ha apreciado la presencia de la categoría del acto político:

- RD de disolución de las Cortes generales (STS 24 de septiembre de 1984).

- Actualización de rentas urbanas (STS 6 de noviembre de 1984).

- Omisión de información gubernamental a parlamentarios autonómicos (STS 9 de junio de 1987). 
- Decreto de fijación provisional de la sede de capitalidad de Comunidad Autónoma de Castilla y León (STS 30 de julio de 1987).

- Petición de revisión de coeficiente funcional (STS 13 de marzo 1990).

- Fijación de salario mínimo interprofesional (STS de $2+$ de julio de 1991).

Pero si parece clara la existencia de actos políticos no controbbles jurisdiccionalmente en euanto al fondo de la decisión, persisten dudas sobre el control de sus elementos reglados. Así la STS de 22 de mero de 1993 que contemplaba la denegación por el (;obierno de la celebración de un referéndum municipal para la incorporación de un municipio a ma Comunidad Autónoma rechaza la excepeión de falta de jurisdicción argumentando que tras la Constitución. y de acuerdo con sus arts. 9.1 y 24. en nuestro Derecho no existen actos de los poderes públicos no sometidos al ordenamiento jurídico y, en consecuencia, exentos del control juriscliccional. Ello no excluye que existan actos de los máximos órganos constitucionales que tengan, asimismo. un máximo contenido político, los cuales no son controlables respecto al fondo de la decisión en sede jurisdiccional, sino ante la instancia política correspondiente. "Pero en cuanto dichos actos contengan elementos reglados establecidos por el ordenamiento, estos elementos sí son susceptibles de control jurisdiceional. Ello implica que la doctrina del acto político no puede ser invocada como fundamento de la inadmisibilidad, ya que es obligado para el juzgador comprobar si existen en el acto elementos reglados y comprobar también si en cuanto al fondo se da ese contenido político no controlable".

Por otra parte, debe tenerse en cuenta que las indemnizaciones derivadas de los actos de gestión política del Cobierno y de los Consejos de Gobierno de las Comunidades Autónomas sí pueden ser objeto de pretensión en vía contencioso-administrativa.

C. La nueva regulación de la jurisdicción contencioso-administrativa debe considerar la nueva atribución de competencia respecto de la responsabilidad patrimonial de la Administración.

Como es sabido, el art". 41 LRJAE, morlificando el criterio del art". 3b) I.JCA, atribuyó a los Tribunales civiles el conocimiento de la respon- 
sabilidad del Estado cuando actuara en las relaciones de Derecho privado.

Sin embargo, la LRJ y. PAC : deroga, entre otros, establece en el art”. 1+t que la responsabilidad de Derecho privado de la Administración se exigirá de conformidad con lo previsto en los arts. 142 y 143 que se refieren al procedimiento administrativo de petición de responsabilidad patrimonial de la Administración, señalando, de manera concreta el art". 142.6 que la resolución administrativa de dichos procedimientos, cualesquiera que fuese el tipo de relación, pública o privada, de que derive, pone lin a la vía administrativa.

2. Dentro de los órganos de la jurisdicción

A. Debe contemplarse la creación de los Juzgados de lo Contencioso-administrativo. que es la última de las reformas orgánicas introducidas por la LOP.I pendiente aún de efectividad.

La existencia de estos órganos judiciales supondrá, como ha dicho el CCPJ. el reconocimiento de un espacio razonable a la doble insiancia. precisa para dar todo su sentido al recurso de casación.

Por otra parte, no debe olvidarse que es necesaria la plena adaptación de la organización judicial y los mecanismos procesales de impugnación, en coherencia con el Estado que diseñan el Título VIII de la Constitución y los Estatutos de Autonomía, al art". 152.1 Cl: que estatblece, en su último párralo que, sin perjuicio de lo dispuesto en el art". 123. las sucesivas instancias procesales han de agotarse ante órganos judiciales radicados en el mismo territorio de la Comunidad en que esté el órgano competente en primera instancia. En consecuencia, debe entenderse que el precepto constitucional reserva las competencias que por su propio carácter corresponden al Tribumal Supremo, orientando ol establecimiento de las instancias en el propio ámbito territorial de la Comunidad Autónoma, cuya organización judicial culmina el Tribunal Superior de Justicia.

La determinación de la competencia de los Juzgados de lo contencioso-administrativo como la de los demás Tribunales contencioso-administrativos, no debe seguir como único criterio el de la jerarquía y ámbito territorial del órgano que dicta el acto o disposición impugnada. 
Así, no parece oportuno que se reserve para los Juzgados el llamado contencioso local, como parece resultar de la cláusula residual del art". 91 LOPJ con la inclusión del planeamiento urbanístico o las ordenanzas locales. Por el contrario, sería más adecuado atribuirle determinadas materias, como: cuestiones de personal al servicio de cualquier Administración pública, salvo los procesos que tuvieran por objeto el nacimiento o la extinción de la relación funcionarial; determinadas sanciones, con independencia de la Administración que las imponga; y algunos actos de la Administración local, como los de aplicación y efectividad de tributos y precios públicos de las Entidades locales, y licencias municipales.

B. Deben resolverse los problemas surgidos en torno a los límites de competencia entre las Salas de los Tribunales Superiores de Justicia y la de la Audiencia Nacional.

Como es sabido, la DT 34 de la LOPJ mantuvo la organización y competencia de los órganos judiciales existentes hasta la entrada en vigor de la Ley 38/1988, de 28 de diciembre (LDP), que se produjo a los veinte días de la publicación, pero al no cumplirse, sin embargo, la prevista creación de los Juzgados de lo Contencioso-administrativo, surgieron las mencionadas dudas, sobre las que se pronunció el Tribunal Supremo señalando:

a) Las Salas de lo Contencioso-administrativo de los Tribunales de Justicia asumieron las competencias atribuidas por el art". 74 LOPJ y además las que podían corresponder a los Juzgados de lo Contencioso.

b) La competencia de la Sala de la Audiencia Nacional es la que establece el art ${ }^{\circ}$. $66 \mathrm{LOPJ}$, sin que pueda considerarse que conserve residualmente competencias nacidas del Real Decreto Ley 1/77, de 4 de enero, por el que fue creada (SSTS 8, 10 y 20 de julio de 1991, entre otras muchas).

Las Salas de los Tribunales Superiores de Justicia podrían conocer, en única instancia: los recursos contra disposiciones generales emanadas de las Comunidades Autónomas y de las Entidades locales; los actos de las Entidades locales y de las Administraciones de las Comunidades Autónomas, cuyo conocimiento no esté atribuido a los Juzgados de lo contencioso-administrativo; los actos de los órganos de gobierno de las Asambleas legislativas de las CCAA en materia de gestión patrimonial y de personal y los actos 
procedentes de órganos de la Administración del Estado cuya competencia no se extienda a todo el territorio nacional, además de aquellas actuaciones no atribuidas expresamente a la competencia de otros órganos.

En segunda instancia los recursos que se promuevan contra sentencias y autos susceptibles de apelación de los Juzgados Cotencioso-administrativo con sede en la C.A.

La Sala de la A.N. tendría la competencia para conocer: los recursos contra disposiciones generales de la Administración del Estado y actos dictados por Ministros y por los órganos centrales de las Corporaciones e Instituciones públicas vinculadas al Estado, así como las resoluciones del Tribunal Económico-administrativo Central.

La Sala $3^{a}$ del TS, en única instancia, conocería las disposiciones y actos del Consejo de Ministros y sus Comisiones Delegadas, actos del CGPJ, de los órganos de gobierno del Congreso y Senado, del TC, del Tribunal de Cuentas y del Defensor del Pueblo. Asimismo, los recursos de casación, ordinario para la unificación de doctrina y en interés de ley y recurso de revisión visión.

En cuanto a los efectos de la falta de competencia, debe favorecerse el mantenimiento de la acción y la conservación de los actos procesales. La declaración de incompetencia debe hacerse antes de dictarse sentencia y con remisión de las actuaciones al órgano competente para que se siga ante él el curso de los autos (SSTC 39/2985 y 109/1985).

3. En relación con las partes:

A. Debe suprimirse la referencia a las implícitas limitaciones de capacidad de la mujer casada que refleja el art ${ }^{\circ} .27$ de LJCA, obviamente derogadas. y contemplarse los supuestos de las uniones sin personalidad para las que la jurisprudencia ha exigido la concurrencia en el proceso de todos sus integrantes o de uno de ellos apoderado por los demás (STS 27 de noviembre de 1985).

B. La legitimación en el proceso contencioso-administrativo ha sido ampliada por la Constitución en varios aspectos y así debe figurar en la futura regulación del proceso contencioso-administrativo. 
a) Aunque el interés directo requerido por el $\operatorname{art}^{\circ}$. 28.1.a) LJCA se ha concebido por la jurisprudencia en términos de gran amplitud, reconociéndole a todo aquel que pueda obtener algún beneficio, cualquiera que sea su naturaleza, de una sentencia favorable, al consagración de la tutela judicial efectiva del interés legítimo en el art $^{\circ} .24 .1 \mathrm{CE}$ ha supuesto la extensión de la legitimación al simple o mero interés legítimo (STC 60/1982).

Una STS de 1 de junio de 1985, tras señalar que a partir de la Constitución se ha extendido la legitimación a la defensa de los intereses legítimos, concepto que es mucho más amplio que el de interés directo, trata de perfilar el concepto de interés legítimo señalando que, según la doctrina tradicional es aquel que tienen aquellas personas que por razón de la situación objetiva en que se encuentra, por una circunstancia de carácter personal o por ser los destinatarios de una regulación sectorial, son titulares de un interés propio, distinto del de cualquier ciudadano en que los poderes públicos actúen de acuerdo con el ordenamiento, aun cuando la actuación de que se trata no les ocasione, en concreto, un beneficio o servicio inmediato.

b) El art a $^{\circ}$ 7.3 LOPJ ya introdujo expresamente la protección de los intereses legítimos colectivos, para cuya defensa se reconoce legitimación a las corporaciones, asociaciones y grupos que resulten afectados o que estén legalmente habilitados para su defensa y promoción.

Se trata del interés de grupos profesionales y económicos, encarnados ordinariamente en entes o corporaciones representativas, que no son una simple suma de intereses personales, sino algo cualitativamente diverso. Afectan por igual y en común a todos los miembros del grupo y pertenecen por entero a todos ellos. Pertenecen. como los intereses difusos a una pluralidad de sujetos, pero a diferencia de éstos pueden ser determinados en una colectividad (intereses de categoría).

Los intereses difusos corresponden por igual a todos los ciudadanos y tienen un reconocimiento jurídico, normalmente en normas constitucionales. Estos intereses reflejos, relacionados con el Estado social, requieren el reconocimiento de una acción popular para su defensa, e, incluso de la legitimación del Ministerio Fiscal y del Defensor del Pueblo. 
c) En cuanto a la legitimación corporativa exigida por el $\operatorname{art}^{\circ} .28 .1$ b) LJCA para la impugnación directa de disposiciones de carácter general de la Administración Central, la más reciente jurisprudencia la ha considerado como obstáculo contrario al art ${ }^{\circ} .24 .1 \mathrm{CE}$. Así la STS de 15 de julio de 1986 entiende que ha quedado derogada por el Texto Constitucional y que es suficiente la legitimación común. No cabe ignorar, sin embargo, que otras sentencias se han manifestado a favor de la pervivencia de la indicada legitimación especial, por lo que también el Tribunal Supremo alude simplemente a la "crisis de que se ha hecho eco la jurisprudencia sobre la vigencia postconstitucional del $\operatorname{art}^{\circ} .28 .1 \mathrm{~b}$ )".

d) También debe reconocerse expresamente la legitimación de las Entidades administrativas para impugnar los actos de otras Administraciones.

La legitimación de la Administración del Estado está reconocida con carácter general frente a las Comunidades Autónomas por la Ley $34 / 1981$, sin que se someta a limitación alguna. Por el contrario, respecto de las Comunidades Autónomas, la misma Ley requiere que se trate de "impugnar las disposiciones de carácter general que, dictadas por la Administración del Estado, afecten al ámbito de su autonomía”.

En la Administración Local, la LRBRL reconoce al Estado legitimación para la impugnación de los acuerdos, previo requerimiento, cuando un acto de la Entidad local infrinja el ordenamiento jurídico ( $\operatorname{art}^{0} .65$ ) y, sin previo requerimiento, cuando los actos y acuerdos de las Entidades Locales menoscaben competencias de la Administración estatal. Además, el art $^{\circ}$. 67 faculta al Delegado del Gobierno para impugnar los actos y acuerdos que "atenten gravemente al interés general de España".

También deberían aplicarse las reglas generales sobre legitimación a la impugnación por las Entidades Locales de los actos de cualquier Administración y no sólo cuando afecten a su autonomía, sino también cuando exista un interés directo en la impugnación.

4. Objeto del proceso contencioso-administrativo.

A. La cláusula general del art ${ }^{\circ} .106 \mathrm{CE}$ y el reconocimiento como derecho fundamental de la tutela judicial efectiva en el art ${ }^{\circ}$. 24.1 CE han supuesto, 
en palabras de Sentencia del Tribunal Supremo de $\overline{5}$ de octubre de 1982, el no mantenimiento de "actos o zonas inmunes al control judicial".

El art". 40 LJCA debe considerarse derogado en lo que se refiere a "materias excluidas", como ha tenido ocasión de señalar el TC de forma concreta en relación con los apartados d) y f) (ATC 60/1980 y 75/1984 y SSTC 39/1983 y 80/1983) con argumentos generalizables a los restantes apartados, salvo el a) y el b).

Consecuentemente, sólo deberían mantenerse la inadmisibilidad del recurso respecto de los actos confirmatorios de otros anteriores firmes, que no hayan sido recurridos en tiempo y forma, y aquellos otros que sean impugnables en otra vía judicial.

B. Junto a los actos administrativos en sentido estricto, deben también considerarse susceptibles de revisión judicial en vía contencioso-administrativa las actuaciones materiales de la Administración y su propia inactividad en determinados supuestos.

a) Según la doctrina tradicional, si la Administración realizaba una actividad material sin previo acto que sirviera de título, es decir, si actuaba por vía de hecho, no cabía acudir directamente al recurso contencioso-administrativo, porque el carácter revisor de éste exigía un acto administrativo previo que pudiera impugnarse. Había, por tanto, que crear un acto administrativo, presentando la correspondiente solicitud y acudiendo, en su caso a la técnica del silencio administrativo.

La indefensión que podía resultar de esta concepción, hizo que se considerase que en tales supuestos de vías de hecho la Administración se situase en el ámbito del Derecho privado y que pudiera acudirse a los medios de protección que proporcionaba el proceso civil, especialmente a través de los procesos sumarios e interdictales.

De esta forma el juez civil debía resolver cuestiones realmente ajenas a su jurisdicción y en procedimientos previstos para cuestiones sencillas. cuando se discutían problemas complejos de naturaleza administrativa.

La propia jurisprudencia, apoyándose en la LOTC, ha iniciado la ampliación del recurso contencioso-administrativo para conseguir el control efectivo de las vías de hecho administrativas. 
En lo que se refiere a la protección de los derechos fundamentales frente a la vía de hecho administrativa, la jurisdicción contencioso-administrativa se configura como la "jurisdicción natural". Así resulta de la DT 2.2 LOTC, en virtud de la cual, antes de pasar al recurso de amparo que está abierto a la impugnación de las vías de hecho, es preciso agotar la vía judicial procedente, siendo esta la contencioso-administrativa ordinaria o el procedimiento especial de la Ley de Protección Jurisdiccional de Derechos Fundamentales (LPJDF).

Con carácter general, también en la jurisprudencia se tiende al control de las vías de hecho. Aun cuando cabe encontrar antecedentes en sentencias anteriores (SSTS 7 de febrero de 1978 y 4 de noviembre de 1982), a partir de la STS de 29 de abril de 1987 se admite con naturalidad "la impugnación (ante la jurisdicción contencioso-administrativa) de los actos que se presentan como simple vía de hecho".

Esta concepción amplia del objeto del recurso contencioso-administrativo es también acogida por la STC 160/1991, señalando que hay actos tácitos, esto es, conductas o comportamientos de la Administración que revelan concluyentemente una decisión administrativa previa y que se dan, sobre todo, en las actuaciones que llevan aparejada el uso de la fuerza y la coacción.

b) Debe corregirse la actual regulación del proceso contencioso-administrativo para hacerlo eficaz frente a la mera inactividad administrativa. suprimiendo la necesidad del acto previo e instrumentando medidas cautelares adecuadas para evitar los perjuicios que de ella puedan derivarse.

Incluso en supuestos de actos presuntos con efectos positivos, según el art". 43 LRJ y PAC puede resultar necesaria una ulterior actuación material por parte de la Administración que, en caso de no producirse, debe dar lugar a un posible recurso contencioso-administrativo.

Por su parte, la STC 180/1991 eleva a principio general el que la Administración no puede verse beneficiada por el incumplimiento de su obligación de resolver.

5. En cuanto a la necesidad de agotar la vía administrativa y la interposición de recurso administrativo, como requisito para acudir al 
proceso contencioso, parece que la LRJ y PAC ha efectuado ya una opción que no resulta la más satisfactoria.

De acuerdo con el $\operatorname{art}^{\circ}$. 37 LJCA es necesario haber agotado la vía administrativa para acceder al contencioso, y el art ${ }^{\circ}$. 109 LRJ y PAC señala los actos que ponen fin a la vía administrativa. $\mathrm{Y}$, si bien es cierto que, según las SSTC 21 y 22/1986 no es contrario al art ${ }^{\circ} .24 \mathrm{CE}$ la existencia de una vía administrativa previa como requisito procesal para el acceso a la vía judicial, la técnica seguida es defectuosa.

A. Se suprime el recurso de reposición, cuando la doctrina mayoritaria defendía su conservación con carácter potestativo para el interesado.

B. Establece como regla general la obligatoriedad del recurso administrativo ordinario cuando el órgano que resuelve tiene un superior jerárquico, con lo que el interesado verá normalmente retrasada por tres meses la posibilidad de acudir al recurso contencioso (arts. 107.1 y 117 LRJ y PAC).

C. Resuelve, sin embargo, las dudas suscitadas entorno a la recurribilidad en vía administrativa de los reglamentos, estableciendo en el art". 107.3 que no cabrá contra las disposiciones generales recurso en dicha vía.

6. La actual regulación del procedimiento responde a criterios de sencillez en la tramitación y de respeto a las garantías de defensa. Es ciertamente simplificado y el Tribunal tiene amplios poderes de impulso y decisión.

La lentitud y la quiebra del derecho a un proceso sin dilaciones indebidas ( art $^{\circ} .24 .2 \mathrm{CE}$ ) se produce, más bien, por los tiempos que median entre las actuaciones sin que se adopte decisión alguna.

De acuerdo con la doctrina del TC y del Tribunal Europeo de Derechos Humanos (TEDH) los criterios a tener en cuenta para determinar si se ha vulnerado el mencionado derecho fundamental son: "la complejidad del litigio, la conducta de los litigantes y de las autoridades y las consecuencias que del litigio presuntamente demorado se siguen para aquellos".

En líneas generales, modificado ya el emplazamiento de demandados y coadyuvantes, parece adecuada la regulación del procedimiento, aunque debieran establecerse mecanismos para corregir las demoras indebi- 
das, como los ordinarios retrasos en el envío de los expedientes administrativos, para los que resulta ineficaz la multa coercitiva prevista para la observancia del correspondiente requerimiento.

7. Los artículos 103 y ss. LJGA regulaban la ejecución de sentencias partiendo de que tal ejecución era competencia de la Administración aunque el Tribunal sentenciador, mientras no constase en autos la total ejecución o efectividad de las indemnizaciones señaladas, debía adoptar a instancia de parte, cuantas medidas fueran adecuadas para promoverla y activarla. Incluso, sin perjuicio de ello, la deducción del tanto de culpa que correspondiera por delito de desobediencia para su remisión el Tribunal competente ( rrt $^{\circ} .110$ LJCA).

Al promulgarse la Constitución se planteó la cuestión de si tal regulación era compatible con los arts. 24 y $117.3 \mathrm{CE}$.

El TC entendió, desde la STC 32/1982, que la ejecución de la sentencia o de lo fallado por los Tribunales forma parte del derecho a la tutela judicial efectiva, pero considera también que el sistema de la LJCA era susceptible de una interpretación conforme a la Constitución, lo que excluía su derogación.

Según la STC 26/1983, la naturaleza de la Administración impide la adopción por el órgano jurisdiccional de medidas de coacción a las que podría recurrir si se tratase de simples ciudadanos, pero los privilegios que protegen a la Administración no la sitúan fuera del ordenamiento, ni la eximen de cumplir lo mandado en los fallos judiciales, ni priva a los jueces y Tribunales de medios eficaces para obligar a los titulares de los órganos administrativos a llevar a cabo las actuaciones necesarias para ellos.

A. Los pronunciamientos del TC pueden resumirse en los siguientes términos:

a) La ejecución de las sentencias y resoluciones firmes corresponde a los titulares de la potestad jurisdiccional "haciendo ejecutar lo juzgado", esto es a los Tribunales, según las normas de competencia y procedimiento. El art ${ }^{\circ} .103 \mathrm{LJCA}$ no atribuye al órgano que hubiera dictado el acto o disposición objeto del recurso una potestad para la ejecución 
de las sentencias, sino un deber, y el derecho a la ejecución no puede verse desligado del tiempo en que se obtiene (STC 67/1984).

La Administración no actúa en la ejecución como titular de tal potestad, sino en cumplimiento de un deber de colaboración en la ejecución de lo resuelto, según dispone el art". $118 \mathrm{CE}$.

b) La titularidad de la potestad de ejecución que establece el art". 117.3 $\mathrm{CE}$ hace que la responsabilidad última de la materialización del fallo recaiga sobre el Tribunal, quien ha de adoptar las medidas pertinentes a tal fin.

$\mathrm{Ni}$ siquiera compete al TC precisar las decisiones y medidas oportunas que, en cada caso, hayan de adoptarse en el ejercicio de dicha potestad jurisdiccional ejecutiva, aunque sí le corresponde corregir y reparar las eventuales lesiones del derecho a la tutela judicial efectiva que tenga su origen en el apartamiento, sin causa justificada. de lo establecido en el fallo o en la pasividad o abstención de los órganos judiciales en la adopción de las medidas necesarias para asegurar el cumplimiento de sus fallos.

c) Son exigibles, en primer lugar, las medidas que, conforme al art". $110 \mathrm{LJCA}$, deben tender a que se produzca inicialmente la actuación administrativa. Pero también lo son cuantas medidas sean necesarias, de acuerdo con las leyes, para impedir lo que el Tribunal supremo ha denominado expresivamente como "la insinceridad de la desobediencia disimulada" por parte del órgano administrativo, que se traduce en un cumplimiento defectuoso, puramente aparente, o en formas de inejecución indirecta.

d) En el trámite de ejecución de la sentencia pueden plantearse y, en su caso, deben resolverse los problemas relativos a una ejecución simulada o fraudulenta del fallo judicial, en la medida en que impliquen un incumplimiento efectivo de lo sentenciado, pues repele a la efectividad de la tutela judicial que mediante actuaciones de aquella naturaleza, pueda imponerse sucesiva e indefinidamente al administrado la carga de promover nuevas acciones o recursos para obtener la satisfacción completa de sus derechos e intereses reconocidos por sentencia firme. Si bien no puede pretenderse en incidente de ejecución que se resuelvan cuestiones no abordadas ni decididas en el fallo (STC 125/1987). 
e) Según las SSTC 67/1984 y 109/84, el legislador puede establecer, sin afectar al contenido esencial del derecho, los supuestos en que la identidad del fallo se puede sustituir por una indemnización.

Cuando la ejecución resulte física o jurídicamente imposible no cabe exigir tal ejecución, sin perjuicio de las responsabilidades en que hayan podido incurrir los que hayan causado esa imposibilidad. En este supuesto la imposibilidad debe ser declarada expresamente en resolución motivada por el Tribunal competente (art ${ }^{\circ}$. 107 LJCA) que fijará, en todo caso, la indemnización procedente en aquello en que la sentencia no pueda ser objeto de cumplimiento pleno ( $\operatorname{art}^{\circ}$. 18.2 LOPJ).

f) Los supuestos en los que el Consejo de Ministros puede decretar la suspensión o inejecución de la sentencia, conforme a los arts. 105 LJCA y 18.2 LOPJ, son controlables por los Tribunales.

B. Las medidas a adoptar por el Tribunal para la ejecución de sentencias resultan demasiado inespecíficas en los arts. 103 y ss L.JCA y su integración con lo dispuesto en la LEC, conforme a la DA $6^{\mathrm{a}}$ LJJCA, no resulta satisfactoria.

Basándose en tales artículos, se pueden distinguir tres fases:

a) En los dos primeros meses desde la recepción de la sentencia, el órgano administrativo debe adoptar las medidas necesarias para la ejecución del fallo (art". 105.1.a), incluso la iniciación de la tramitación del oportuno crédito presupuestario (art". 44.3 TRLGP).

El transcurso de dicho plazo sin adoptar las medidas necesarias para la ejecución del fallo origina responsabilidad, que puede ser civil o penal (art'. 109).

b) En los seis meses siguientes a la recepción del testimonio de la sentencia o desde la fijación de la indemnización (art ${ }^{\circ}$. 110.2 LJCA) debe ejecutarse aquella o satisfacer ésta.

c) Transcurridos esos seis meses sin que la Administración lo haya hecho, el Tribunal de acuerdo con el art". 110 LJJCA, está obligado a deducir el tanto de culpa que correspondiere por delito de desobediencia.

En la futura regulación, además de una posible reducción de los indicados plazos, deberían contemplarse previsiones concretas de actua- 
ciones del Tribunal para la ejecución del fallo, según el contenido de éste. En este sentido podrían contemplarse:

- Inscripción de la anulación del acto en todos los registros públicos a que hubiera tenido acceso el acto anulado.

- Publicación de la anulación de disposiciones generales.

- Cuando la ejecución comportase una determinada actividad, la ejecución por el Juez o Tribunal a través de sus propios medios o, en su caso, mediante la colaboración directa de autoridades y agentes de la Administración condena o de otras Administraciones públicas.

- Imposición de multas coercitivas, sin perjuicio de otras responsabilidades patrimoniales o de naturaleza penal.

- Especialmente importantes son los problemas que suscitan la condena a la Administración al pago de cantidad, derivados fundamentalmente:

- Inembargabilidad de caudales públicos ( $\operatorname{art}^{\circ}$. 44 TRLGP y 154.2 LHL).

- El principio de legalidad presupuestaria que, según la STC $107 / 1992$, permite que el legislador, con fundamento objetivo y razonable, pueda impedir que la potestad de ejecución forzosa se dirija contra determinados bienes (continuidad de los servicios públicos), y que, conforme a la STC 61/1984, el pago se supedite a determinados requisitos exigidos por las normas legales que regulan las finanzas públicas y ordenan el gasto público.

Para atender a tales condenas pecuniarias, una de las posibles soluciones sería la consignación en los presupuestos de todas las Administraciones Públicas de créditos suficientes. $\mathrm{Y}$ si fuere preciso un crédito extraordinario o suplemento de crédito, el establecimiento de la obligación de iniciar su tramitación en un plazo determinado.

En todo caso, cuando la resolución condene al pago de una cantidad líquida, ésta devengaría a favor del acreedor un interés anual igual al interés legal incrementando en determinados puntos, desde la sentencia de primera instancia, salvo que ésta fuera revocada en virtud de recurso interpuesto. 
8. Las medidas cautelares constituyen otra de las materias necesitadas de urgente reforma, ante la insuficiencia de las previsiones contenidas en los arts. 122 y ss LJCA.

A. La única medida contemplada en dichos preceptos es la suspensión de la ejecución del acto o disposición objeto del recurso cuando la ejecución pueda ocasionar daños o perjuicios de reparación imposible o difícil.

La jurisprudencia más reciente ha flexibilizado la aplicación de la suspensión, basándose en los siguientes criterios:

a) Necesidad de ponderación suficientemente razonada entre el perjuicio que causaría al interés público o a terceros la suspensión y el perjuicio que se causa al recurrente como consecuencia de la eficacia inmediata del acto recurrido, como señala la $\mathrm{E}$. de $\mathrm{M}$., apartado $\mathrm{V} 7$ de la LJCA y, actualmente, el art”. 111.2 LRJ y PAC (ATC 3 de enero de 1991).

b) El art". 122 LJCA incorpora conceptos jurídicos indeterminados similares a los que se utilizan en Francia (prejudice grave et irreparable) e Italia (damno grave e irreparable). Su aplicación requiere un análisis circunstancial en cada caso de los efectos de la ejecución del acto desde la perspectiva de la reversibilidad de la situación que puede provocar. Pero, con carácter general, la jurisprudencia utiliza los siguientes criterios:

$1^{\circ}$. La existencia del derecho y la seriedad de su fundamentación basta que aparezcan como probables (fumus bonis iuris). Pero la indagación y comprobación de la certeza del daño y el carácter de su irreversibilidad o dificultad de su reversibilidad en el supuesto de que se ejecute el acto requicre la aportación de algún medio de prueba por parte del recurrente. Como regla general, no basta, por tanto, con la mera alegación del daño irreversible o de difícil reparación.

$2^{\circ}$. El que el daño sea económicamente valorable no excluye necesariamente la suspensión, sino que procederá esta medida cautelar cuando la evaluación sea difícil o resulte más gravosa la reparación que la no ejecución.

En el ámbito económico-administrativo, los arts. 80 y 81 del Reglamento establecen que la suspensión de la ejecución se produce a instancia del interesado si en el momento de interponer la reclamación se garantiza, en la forma 
reglamentariamente determinada, el importe de la deuda tributaria, previsión que puede ser trasladable también a la vía contencioso-administrativa.

B. En cualquier caso, como se ha dicho, resulta insuficiente la suspensión prevista en los arts. 122 y ss LJCA para atender a las necesidades de la tutela judicial cautelar, especialmente en los supuestos de actos negativos o ante la mera inactividad de la Administración.

a) Ante esta circunstancia. la doctrina ha propuesto la aplicación al proceso administrativo de otras medidas cautelares, como las previstas en el art". 1428 LEC. El Juez dispondría de un amplísimo margen de decisión, ya que el único límite consiste en la necesidad de la medida. Serían posibles tanto las de carácter conservativo como innovativo.

b) La legislación sectorial ha previsto determinadas medidas cautelares, como por ejemplo el art". 13 de la Ley de Costas que autoriza a los titulares inscritos en el Registro de la Propiedad y afectados por un deslinde para ejercitar las acciones pertinentes en defensa de sus derechos "siendo susceptible de anotación preventiva la correspondiente reclamación judicial".

También en la legislación urbanística, el art”. 307.6 del TRL Suelo establece que es inscribible en el Registro de la Propiedad la interposición del recurso contencioso-administrativo que pretenda la anulación de instrumentos de planeamiento, de ejecución del mismo o de licencias, mediante la anotación preventiva.

En otros supuestos en que, sin estar prevista, resultaría también razonable la anotación preventiva la jurisprudencia contencioso-administrativa ha sido reticente a su admisión.

C. La nueva regulación del proceso contencioso-administrativo debe contemplar expresamente las medidas cautelares, teniendo en cuenta la amplitud con que son previstas en el Derecho comparado. Así:

a) En el Derecho alemán se establecen las órdenes provisionales que pueden dictarse cuando exista peligro de que un cambio de las circunstancias presentes pueda malograr o dificultar sustancialmente el derecho del interesado, y cuando sea necesario una regulación provisional para prevenir perjuicios sustantivos, evitar daños o por otras razones. 
b) En el Derecho francés, el référé administrativo que consiste en un procedimiento por el que el presidente del Tribunal administrativo o de apelación, o el magistrado en quien cualquiera de ellos delegue, adopta, a petición del interesado, cualquier medida útil en caso de urgencia, siempre sin prejuzgar el fondo del asunto y sin que ello pueda ser obstáculo a la ejecución de una decisión administrativa, no siendo necesario que ésta exista, pero sí la existencia de un litigio actual.

La futura Ley debe contemplar la suspensión de la eficacia del acto impugnado en cualquier estado del proceso, previa valoración de los intereses en conflicto: cuando la ejecución del acto o la aplicación de la disposición puedan hacer perder al recurso su legítima finalidad o cuando la ejecución pueda causar al recurrente perjuicios de imposible o difícil reparación.

Pero, además, deben contemplarse otras medidas cautelares cuando como consecuencia de la inactividad o vías de hecho de la Administración Pública resulte afectada la integridad de bienes, derechos o intereses legítimos. En estos casos debería establecerse la posibilidad de adoptar las medidas provisionales que fucran indispensables y adecuadas para preservar aquéllos y asegurar la efectividad de la sentencia que, en su caso, ponga fin el recurso. 